\title{
NMR and Theoretical Study on Conformation of Methacrolein Dimer, 2,5-Dimethyl-3,4-dihydro-2H-pyran-2-carboxyaldehyde
}

\author{
Susumu Sofue, ${ }^{\dagger}$ Terumasa YamasaKI, ${ }^{*}$ Hideo Morita, ${ }^{* *}$ \\ and Yoshiharu Kitahama*** \\ Analytical Research Laboratory, Kawasaki Works, Asahi Chemical Industry Co., Ltd., \\ 1-3-1 Yakoh, Kawasaki-ku, Kawasaki-shi, Kanagawa 210-0863, Japan \\ * Computer Science Department, Asahi Chemical Industry Co., Ltd., \\ 2-1 Samejima, Fuji-shi, Shizuoka 416-8501, Japan \\ ** Synthetic Rubber Department, Kawasaki Works, Asahi Chemical Industry Co., Ltd., \\ 1-3-1 Yakoh, Kawasaki-ku, Kawasaki-shi, Kanagawa 210-0863 Japan \\ ***Japan Elastomer Co., Ltd., 2 Nakanosu, Ooita-shi, Ooita 870-0189 Japan
}

(Received February 18, 1998)

\begin{abstract}
Detailed structures of methacrolein dimer (MAD) were analyzed by nuclear magnetic resonance (NMR) and theoretical calculations. Two dimensional ${ }^{1} \mathrm{H}$ and ${ }^{13} \mathrm{C}$ NMR peaks were assigned. Relative stability of conformations and interconversion barrier height were studied by semi-empirical MNDO and ab initio DFT calculations. Barrier height between pseudoaxial and pseudoequatorial half-chair conformers was $5.8 \mathrm{kcal} \mathrm{mol}^{-1}$. Separations of chemical shifts of two protons bonded to the same methylene carbons became larger as measurement temperature decreased, due to reduced mobility of the ring framework.

KEY WORDS $\quad{ }^{13} \mathrm{C}$ Nuclear Magnetic Resonance / ${ }^{1} \mathrm{H}$ Nuclear Magnetic Resonance / Methacrolein Dimer / Conformational Analysis / Theoretical Calculations /
\end{abstract}

Cationic polymerizations of alkenes are important for preparation of commercial polymers. While many polymers of simple $\alpha$-olefins are obtained by these processes, polymers with cyclic structures in the backbone are limited. Cationic polymerization of methacrolein dimer (MAD) (2,5-dimethyl-3,4-dihydro-2 $H$-pyran-2-carboxyaldehyde) gives bicyclic polymer [IIIA] in good yield at ambient temperature among other possible polymer structures shown below. ${ }^{1,2}$ (For notations of polymer structures, see these references.)

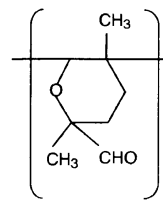

[I]

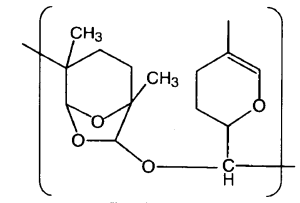

[IIIA]-[II]

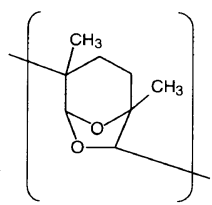

[IIIA]
As MAD became available from several sources at present, polymerization mechanism and conditions of such a unique polymer were studied again in this paper.

MAD has an asymmetric carbon in the ring to which the aldehyde group is bonded. Therefore, MAD has two stereo isomers (enantiomers $S$ and $R$ ) and each isomer takes several conformations arising from ring puckering deformation and rotation of the aldehyde group around the $\mathrm{C}^{*-} \mathrm{CHO}$ axis.

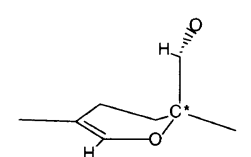

$(S)$

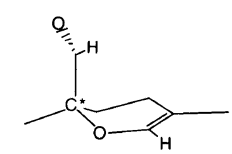

$(R)$

\footnotetext{
+ To whom correspondence should be addressed.
}

As a result of torsional constraint imposed by the double bond in the ring framework, conformational variation in the 3,4-dihydropyran ring is rather limited compared to the oxycyclohexane ring such as pyranose. MAD is also important in oligosaccharides synthesis, ${ }^{3,4}$ but information about the structures and reactivities is surprisingly scarce. In early works, Bushweller and O'Neil assumed the predominant existence of a halfchair conformer for 3,4-dihydropyran based on nuclear magnetic resonance (NMR) spectra $^{5}$ In another NMR measurement, Eliel et al. ${ }^{6,7}$ reported analysis of MAD structures by use of ${ }^{13} \mathrm{C}$ and ${ }^{1} \mathrm{H}$ NMR, but did not give detailed assignments of $\mathrm{CH}_{2}$ and $\mathrm{CH}_{3}$.

3,4-Dihydropyran has been analyzed theoretically only by the force field approach but there is no study on MAD. Force field studies are appropriate for hydrocarbons such as cyclohexane and cyclohexene, but simple force field potential does not well account for oxygen lone pair and double bond $\pi$-electron effects. Highly accurate $a b$ initio calculation is indispensable for determination of the conformer geometries and precise prediction of the barrier height.

This paper focuses on conformational preference and interconversion of MAD molecule after successful assignment of ${ }^{1} \mathrm{H}$ and ${ }^{13} \mathrm{C}$ NMR peaks of MAD. Various conformers of MAD and the interconversion barrier height were determined by electronic structure calculations. NMR and computational results herein set foundations for the reactivity of MAD in cationic polymerization and are discussed in our sequel papers.

\section{EXPERIMENTAL}

\section{Preparation of Methacrolein Dimer}

MAD was prepared by thermal dimerization of dry methacrolein in the presence of hydroquinone $(1 \%$ by weight in methacrolein) at $160^{\circ} \mathrm{C}$ for $3 \mathrm{~h}$ under nitrogen 


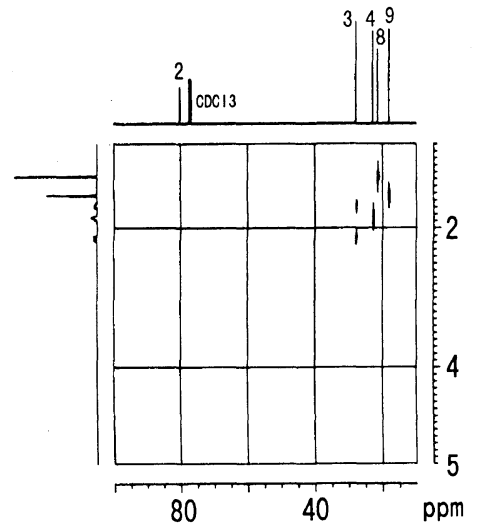

(a)

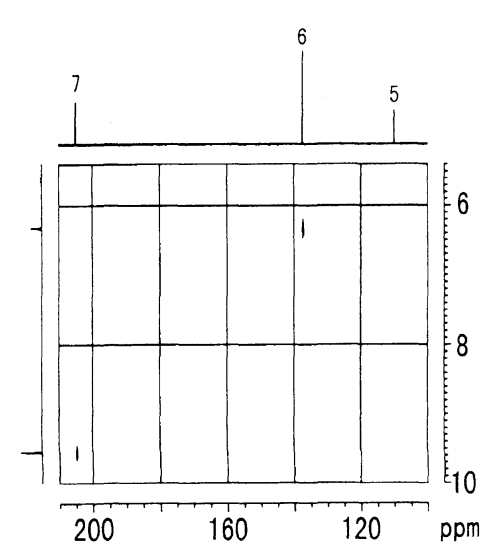

(b)

Figure 1. $\mathrm{CH}$ correlation spectrum of MAD. Numbers on the one dimensional ${ }^{13} \mathrm{C}$ spectrum are based on the structure of MAD appeared in a text. (a) methyl, methylene region; (b) methine region.

pressure and fractionated at $68.1^{\circ} \mathrm{C}$ under $24 \mathrm{~mm} \mathrm{Hg}$.

\section{Method for NMR Measurements}

10 - $100 \mathrm{mg}$ MAD were dissolved in $0.7 \mathrm{ml}$ chloroform$d_{1}$, and ${ }^{1} \mathrm{H}$ and ${ }^{13} \mathrm{C}$ NMR spectra were recorded with a BRUKER DPX400 spectrometer operated at ${ }^{1} \mathrm{H}$ frequency of $400 \mathrm{MHz}$ at room temperature, except for INADEQUATE and variable temperature experiments. INADEQUATE was performed by dissolving $300 \mathrm{mg}$ samples in $0.5 \mathrm{ml}$ chloroform- $d_{1}$ with a JEOL JNMEX270 spectrometer operating at $270 \mathrm{MHz}$ at $30^{\circ} \mathrm{C}$. Tetramethylsilane (TMS) peak at $0 \mathrm{ppm}$ was used as reference for the spectra. This paper analyzes variable temperature ${ }^{1} \mathrm{H}$ NMR spectra at $30,0,-55$, and $-80^{\circ} \mathrm{C}$ by dissolving $10 \mathrm{mg}$ samples in toluene- $d_{8}$, with the JEOL spectrometer equipped with a temperature controller. The samples were stabilized at the measurement temperature at least $15 \mathrm{~min}$ before measurement. Methyl peak of toluene at $2.3 \mathrm{ppm}$ was used as reference for the spectra.

\section{Details of Electronic Structure Calculations}

Electronic structures were calculated at semi-empirical MNDO/AM1 and $a b$ initio Density Functional Theory (DFT) levels. Total energy for a molecule is calculated with these methodologies in UniChem/MNDO94 and UniChem/Dgauss programs, running on SGI/Cray J90 and T90 systems ${ }^{8}$. DFT calculations were based on the

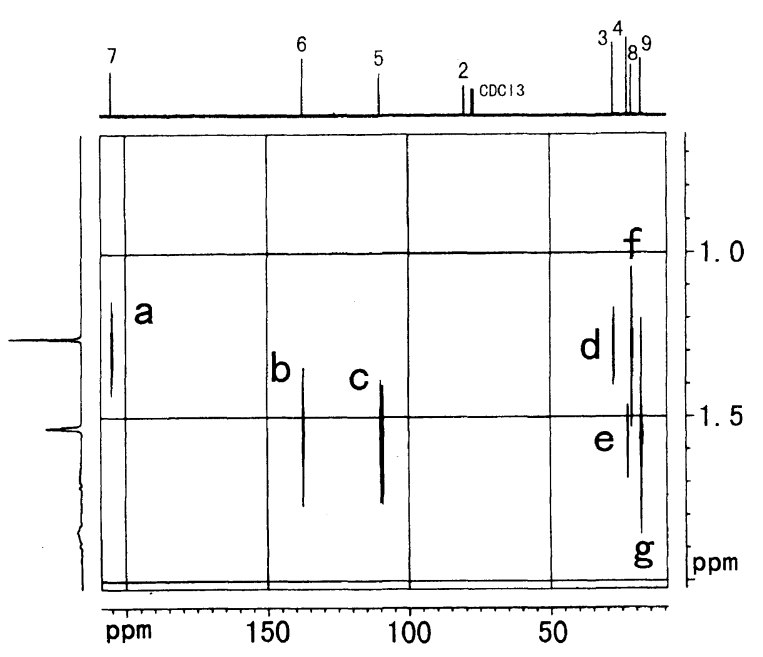

Figure 2. COLOC spectrum of MAD.

self-consistent, non-local DFT formalism of BeckePerdew $^{9}$ with valence double zeta plus polarization basis functions (DZVP/A1). ${ }^{8}$ Molecular geometries are optimized by the same method.

\section{RESULTS AND DISCUSSION}

Assignments of ${ }^{13} \mathrm{C}$ and ${ }^{1} \mathrm{H} N \mathrm{NM}$ Spectra of $M A D$

To fully understand conformational change of the MAD molecule, complete assignment must be made at first. MAD has two methylene carbons and two methyl carbons in almost the same magnetic environment, and thus 2D NMR spectroscopy was necessary.

Figure 1 shows two dimensional ${ }^{1} \mathrm{H}-{ }^{13} \mathrm{C}$ correlation spectra with the corresponding ${ }^{1} \mathrm{H}$ and ${ }^{13} \mathrm{C}$ one dimensional spectra. Protons and carbons of the unsaturated methine $(6.33,137.4 \mathrm{ppm})$ and aldehyde group $(9.55,205.0 \mathrm{ppm})$, as well as unsaturated $(110.0$ $\mathrm{ppm})$ and saturated $(80.2 \mathrm{ppm})$ quaternary carbons are readily assigned. Two protons connected to the methylene carbon at $28.0 \mathrm{ppm}$ appear separately at 1.7 and $2.1 \mathrm{ppm}$ while those connected to the other methylene carbon have almost the same frequency.

To make clear the assignments of proton peaks of methyl and especially methylene groups, ${ }^{1} \mathrm{H}-{ }^{13} \mathrm{C}$ correlation via long-range (COLOC) spectrum of MAD was measured. Figure 2 shows five long-range correlation peaks in addition to direct coupling peaks $f$ and $g$. Peak $a$ shows long-range coupling of C8 methyl protons with the aldehyde carbon, while peak $b$ that of C9 methyl protons with $\mathrm{C} 6$ methine carbon as shown below.<smiles>CC1=CCCCC1(C)C</smiles>

Resonance at $1.26 \mathrm{ppm}$ in ${ }^{1} \mathrm{H}$ spectrum was thus assigned to $\mathrm{C} 8$ methyl protons, and resonance at $1.53 \mathrm{ppm}$ C9 methyl protons. Peak $c$ shows correlation between C9 methyl protons and C5 quaternary carbon.

Peaks $d$ and $e$ show long-range couplings of the methylene carbon at $28.0 \mathrm{ppm}$ to C9 methyl protons and 


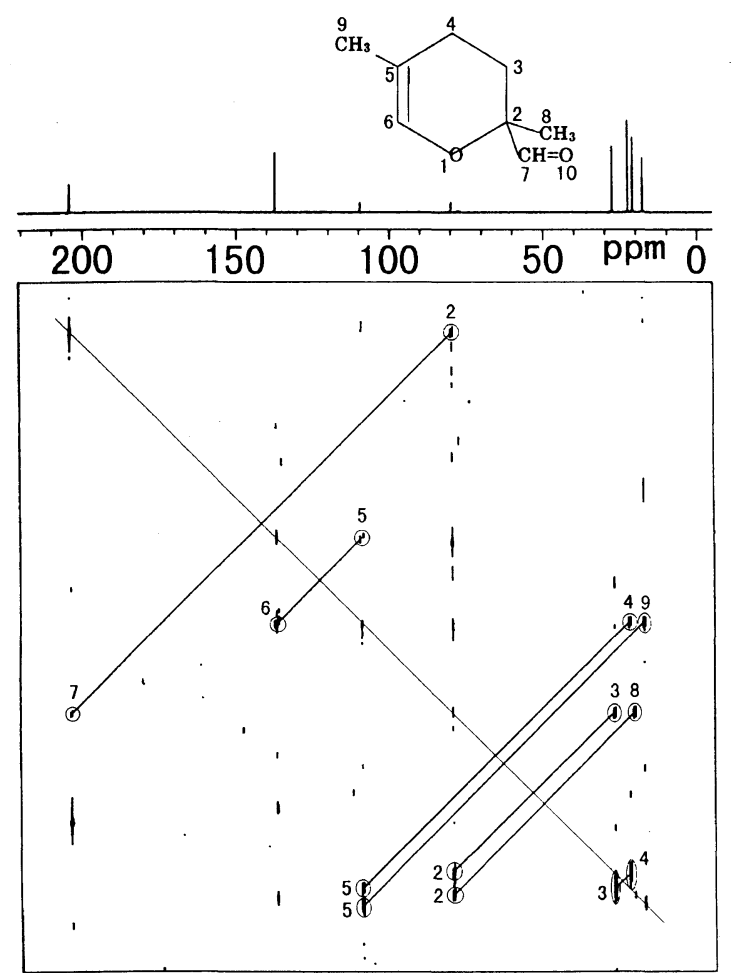

Figure 3. INADEQUATE spectrum of MAD with its structure. Connectivity of carbon atoms is represented by 7 bold lines.

Table I. Data for assignments of NMR spectra of MAD (in chloroform- $d_{1}, 30^{\circ} \mathrm{C}$ )

\begin{tabular}{cccccc}
\hline & \multicolumn{2}{c}{${ }^{13} \mathrm{C} N M R$} & & \multicolumn{2}{c}{${ }^{1} \mathrm{H} \mathrm{NMR}^{\mathrm{d}}$} \\
\cline { 2 - 3 } \cline { 5 - 6 } Position $^{\mathrm{a}}{ }^{2}$ & $\begin{array}{c}\text { Chemical } \\
\text { shift } / \text { ppm }^{\mathrm{b}}\end{array}$ & $\begin{array}{c}\text { Atomic } \\
\text { group }^{\mathrm{c}}\end{array}$ & & $\begin{array}{c}\text { Chemical } \\
\text { shift/ppm }\end{array}$ & Intensity \\
\hline 2 & 80.2 & $\mathrm{C}$ & & - & 0 \\
3 & 28.0 & $\mathrm{CH}_{2}$ & & 1.7 & 1 \\
& & & & 2.1 & 1 \\
4 & 23.0 & $\mathrm{CH}_{2}$ & & 1.85 & 2 \\
5 & 110.0 & $\mathrm{C}$ & & - & 0 \\
6 & 137.4 & $\mathrm{CH}$ & & 6.33 & 1 \\
7 & 205.0 & $\mathrm{CH}$ & & 9.55 & 1 \\
8 & 21.5 & $\mathrm{CH}_{3}$ & & 1.26 & 3 \\
9 & 18.2 & $\mathrm{CH}_{3}$ & & 1.53 & 3 \\
\hline
\end{tabular}

${ }^{a}$ Based on the structure of MAD in the text. ${ }^{b}$ Complete decoupled ${ }^{13} \mathrm{C}$ NMR. $\quad{ }^{\mathrm{c}}$ Results of DEPT experiments. ${ }^{\mathrm{d}}{ }^{1} \mathrm{H}$ NMR, $\mathrm{CH}$ correlation.

the other methylene carbon at $23.0 \mathrm{ppm}$ to $\mathrm{C} 8$ methyl protons. Thus the former carbon is assigned to $\mathrm{C} 4$ methylene carbon, while the latter to $\mathrm{C} 3$ methylene carbon.

Assignments of carbon resonances were clarified by 2D-INADEQUATE spectrum as shown in Figure 3. The observed connectivities in the INADEQUATE spectrum are depicted in the figure. The results are consistent with those obtained by COLOC method. ${ }^{1} \mathrm{H}$ and ${ }^{13} \mathrm{C}$ chemical shifts are summarized in Table I.

Low Temperature NMR Measurement and Interconversion of Two Conformers

Although basic assignments of NMR spectra were made in chloroform for comparison with the spectrum of polymer recorded in the past, variable temperature

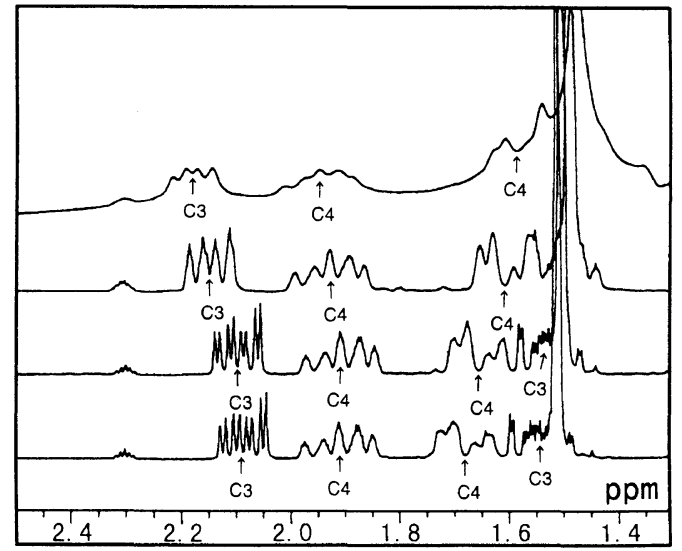

Figure 4. ${ }^{1} \mathrm{H}$ NMR spectra of MAD in toluene- $d_{8}$ at $+30,0,-55$, and $-80^{\circ} \mathrm{C}$ (from bottom to top).

measurement demanded measurement in another solvent with lower freezing point than that of chloroform. ${ }^{1} \mathrm{H}$ spectra in toluene- $d_{8}$ at low temperature down to $-80^{\circ} \mathrm{C}$ are shown in Figure 4. Spectrum pattern of methylene region in toluene was different from that in chloroform. ${ }^{1} \mathrm{H}$ resonances of $\mathrm{C} 3$ methylene were found at 1.5 and $2.1 \mathrm{ppm}$, while those of $\mathrm{C} 4$ methylene at 1.7 and $1.9 \mathrm{ppm}$ at $30^{\circ} \mathrm{C}$. This assignment was confirmed by the $\mathrm{CH}$ correlation spectrum and ${ }^{13} \mathrm{C}$ NMR spectrum, which showed almost the same pattern despite differences in solvents. These shifts come from differences in two protons bonded to methylene carbons. C3 methylene protons closer to the aldehyde group give larger differences of chemical shifts than that of $\mathrm{C} 4$ ones at each temperature. When interconversion occurs between pseudoaxial and pseudoequatorial conformers, the differences become smaller as a result of averaged magnetic environment of the two protons. The differences were larger with decreasing temperature down to $-80^{\circ} \mathrm{C}$, suggesting more frozen interconversion with temperature decrease. Activation energy of this interconversion was estimated by ab initio calculations (vide infra).

Calibration of Theoretical Calculation with Cyclohexene

In unsaturated six-membered ring molecules, structures of cyclohexene have been extensively studied by spectroscopy (IR, NMR) and theoretical computations (force field, electronic structure calculations). It is generally accepted that cyclohexene exists in half-chair conformers ( $\mathrm{C} 2$ point group symmetry) and these conformers interchange via the boat structure ${ }^{10}$ (eq 1).

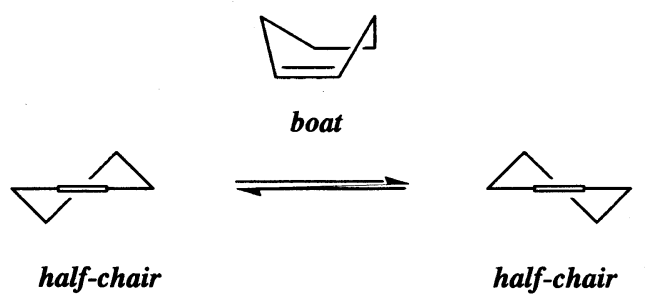

These half-chairs and boat conformers are sometimes called twist and bent structures, respectively. ${ }^{11}$ Anet $e t$ al. estimated the energy barrier for interconversion to be $5.3-5.6 \mathrm{kcal} \mathrm{mol}^{-1}$ by dynamic NMR measurement and $5.4-5.7 \mathrm{kcal} \mathrm{mol}^{-1}$ by theoretical calculations. ${ }^{12}$ It is 

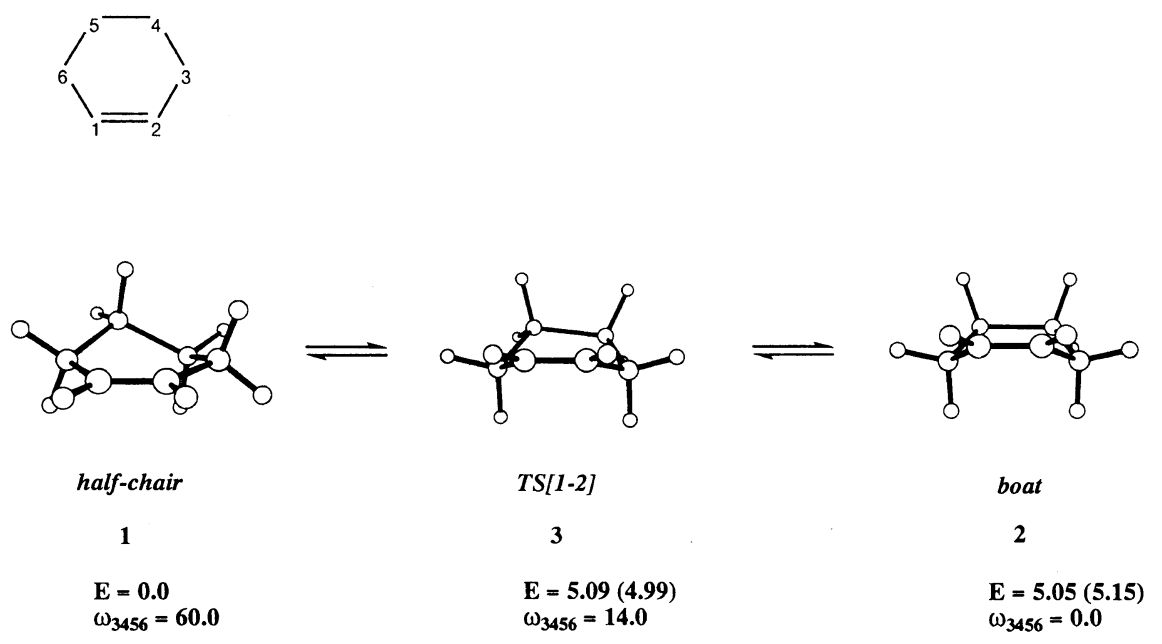

Figure 5. Relative stability of conformers in cyclohexene ring inversion process. Molecular structures are optimized by non-local DFT calculations. Energy values are total energy in DFT calculation and total energy plus ZPE correction (in parenthesis). Unit in $\mathrm{kcal} \mathrm{mol}^{-1}$ and ${ }^{\circ} \mathrm{C}$.

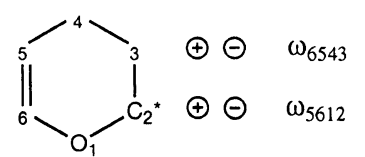

deg. of freedom $=\omega_{6543} \otimes \omega_{5612}$

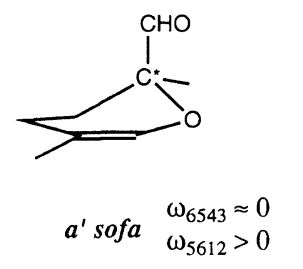

7

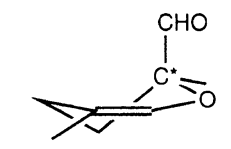

$\begin{array}{cc}\boldsymbol{a}^{\prime} \text { half-chair } & \omega_{6543}>0 \\ \mathbf{4} & \omega_{5612}>0\end{array}$
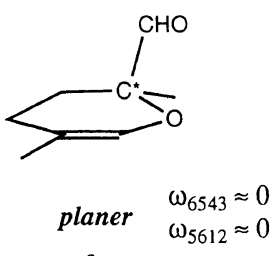

9

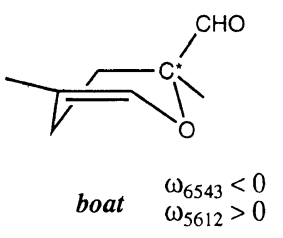

6
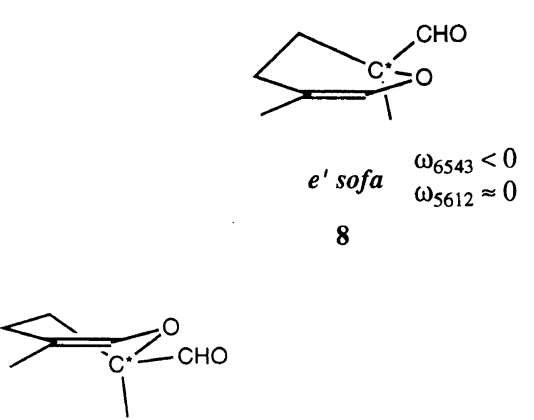

$\begin{array}{cl}\boldsymbol{e}^{\prime} \text { half-chair } & \omega_{6543}<0 \\ \omega_{5612}<0\end{array}$

5

Figure 6. Two-dimensional potential energy surface (PES) scan scheme for 3,4-dihydropyran ring framework. Possible conformers of MAD are designated by two dihedral angles, $\omega_{6543}$ and $\omega_{5612}$, on the PES.

also argued by several authors that the symmetric boat form $\left(\mathrm{C}_{\mathrm{s}}\right.$ point group symmetry) is either a transition state between the two half-chair conformers or an intermediate state and real transition states exist in-between the half-chair and boat forms. This point is not clear, but information up to now suggests instability of the boat form. This study calculated interconversion barrier height of cyclohexene for comparison with those in other works. We carried out potential energy surface (PES) scans with selected degrees of freedom and MNDO/AM1 calculations. Obtained critical points at the MNDO/AM1 PES are re-optimized with non-local DFT calculations. Final conformer geometries and energies for cyclohexene are given in Figure 5.

The results in Figure 5 are somewhat confusing. DFT energy suggests that the boat form is a shallow minimum, i.e., intermediate with very small differences in energy
$\left(\Delta E=0.04 \mathrm{kcal} \mathrm{mol}^{-1}\right)$, along the interconversion pathway to vicinal real transition state. However, if zero point energy (ZPE) correction is added to pure DFT energy, the transition state is slightly more stable than the intermediate state.

In summary, our results show a very flat topped energy profile in agreement with the previous work by Anet et al. The barrier height was $5.2 \mathrm{kcal} \mathrm{mol}^{-1}$ based on ZPE corrected value. The same method was used in the following theoretical calculation of MAD.

\section{Conformational Analysis of $M A D$}

Due to the asymmetric carbon in the ring, MAD exists in two isomer forms, enantiomers of each other. This study dealt with only the $S$ form.

The geometry and energetics of MAD ring framework are studied analogously to the conformational analysis 
of cyclohexene. Half-chair, boat, sofa, and planer forms are possible as local minima or transition states. ${ }^{10}$ The sofa and planer forms are not likely critical point geometries for the 3,4-dihydropyran ring, but several local minima of the sofa were reported for pyran derivatives. ${ }^{13}$

To cover all candidate conformers, this paper set up two-dimensional PES scans as shown in Figure 6 and calculated at MNDO/AM1. In this scheme, two dihedral

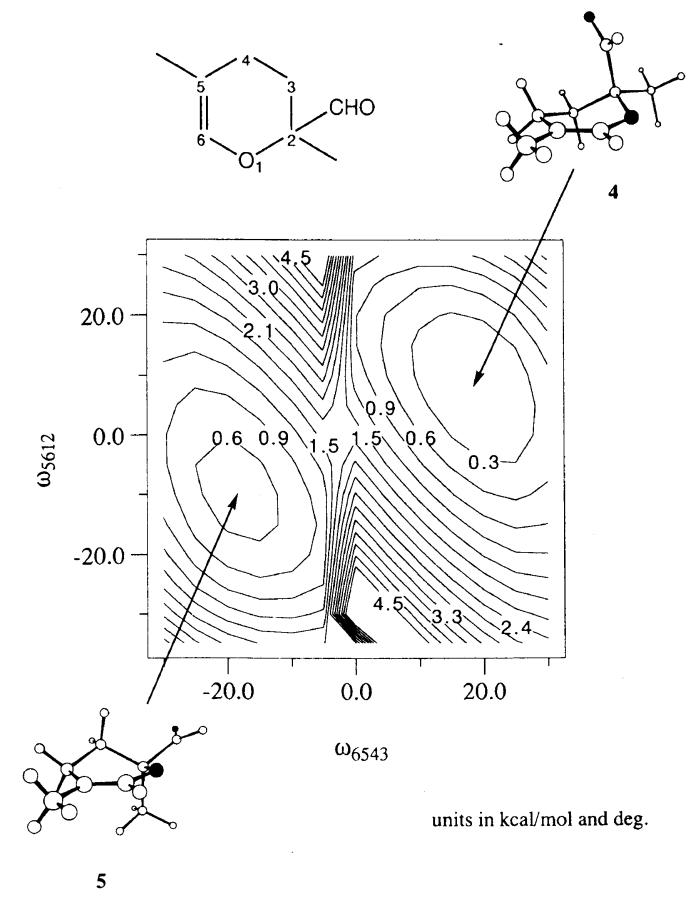

Figure 7. Two-dimensional potential energy surface (PES) of MAD calculated with MNDO/AM1 method. angles, $\omega_{6543}$ and $\omega_{5612}$, were varied by $5 \mathrm{deg}$ at each step. Rotation of the aldehyde group was treated separately. Figure 7 shows the obtained energy profile for ring deformation. PES clearly designates two minima, corresponding to the half-chair conformers. The transition state occurs around $\omega_{5612} \sim 0$ and $\omega_{6543}<0$. The lowest energy path seems to connect the half-chair minima via the boat/sofa transition state. The planer form is neither a stable nor transitional state (TS). It is

Table II. Selected dihedral angles of MAD conformers (degree)

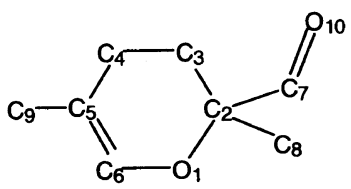

\begin{tabular}{cr|cr}
\hline trans a' half-chair (4A) & & trans $\mathrm{e}^{\prime}$ half-chair (5A) \\
C5-C6-O1-C2 & 13.6 & C5-C6-O1-C2 & -11.8 \\
C6-C5-C4-C3 & 12.5 & C6-C5-C4-C3 & -14.9 \\
O1-C2-C7-O10 & -175.6 & O1-C2-C7-O10 & 171.0 \\
O1-C2-C3-C4 & 58.3 & O1-C2-C3-C4 & -57.8 \\
Boat (6A) & & Boat (6B) & \\
C5-C6-O1-C2 & 40.4 & C5-C6-O1-C2 & 40.4 \\
C6-C5-C4-C3 & -37.1 & C6-C5-C4-C3 & -37.1 \\
O1-C2-C7-O10 & -170.9 & O1-C2-C7-O10 & -2.3 \\
O1-C2-C3-C4 & 8.3 & O1-C2-C3-C4 & 8.3 \\
cis a' half-chair (4B) & & cis $\mathrm{e}^{\prime}$ half-chair (5B) & \\
C5-C6-O1-C2 & 15.5 & C5-C6-O1-C2 & -12.3 \\
C6-C5-C4-C3 & 13.6 & C6-C5-C4-C3 & -13.7 \\
O1-C2-C7-O10 & 5.4 & O1-C2-C7-O10 & 0.0 \\
O1-C2-C3-C4 & 58.1 & O1-C2-C3-C4 & -58.2 \\
TS [4A-4B]a & & TS [5A-5B]a & \\
O1-C2-C7-O10 & -57.6 & O1-C2-C7-O10 & -41.0 \\
TS [4A-4B]b & & TS [5A-5B]b & \\
O1-C2-C7-O10 & 67.0 & O1-C2-C7-O10 & 58.0 \\
\hline
\end{tabular}

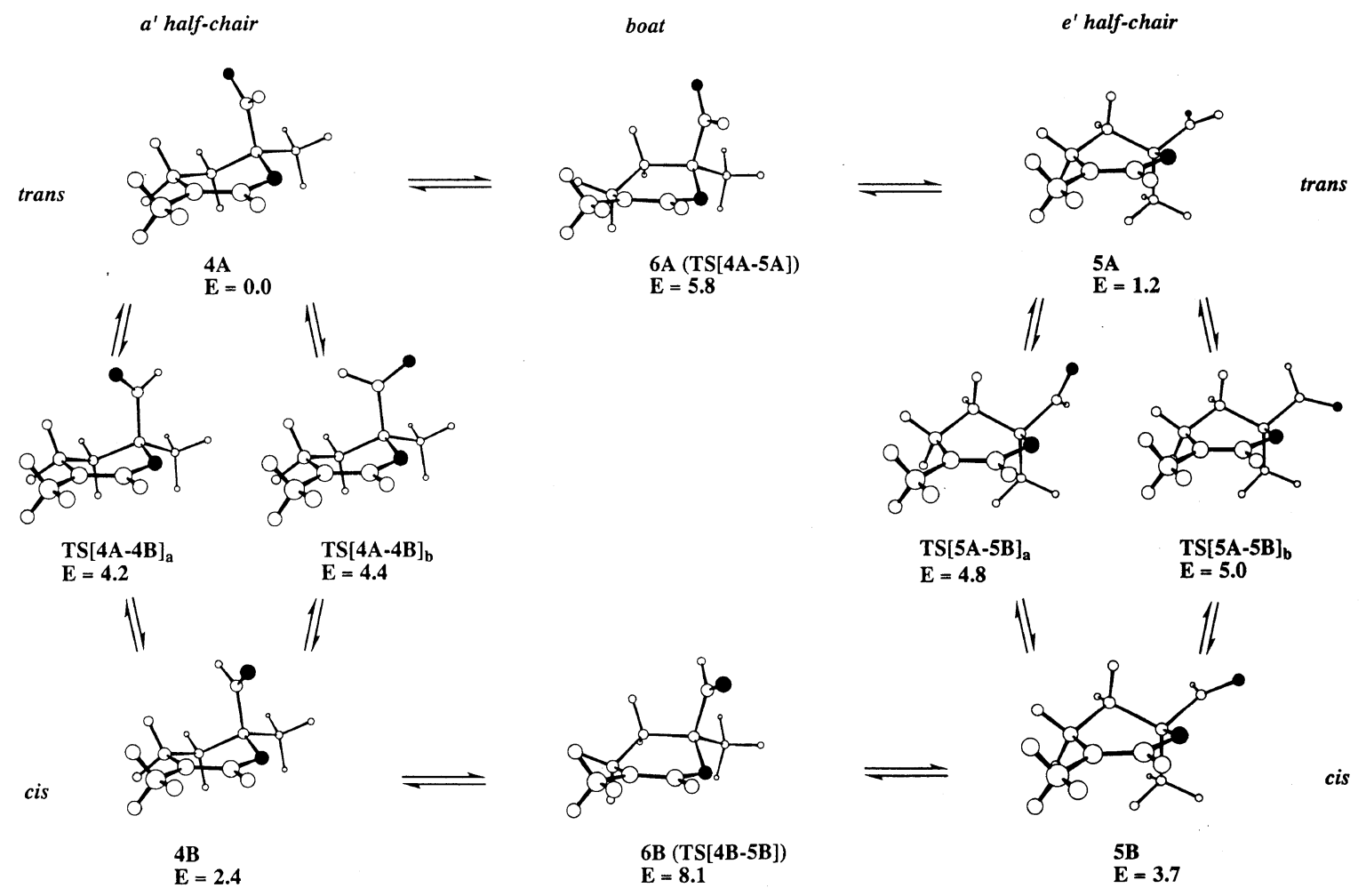

Figure 8. Relative stability of MAD conformers located by non-local DFT calculations. Energy values are corrected for ZPE. $a^{\prime}$ and $e^{\prime}$ denote pseudoaxial and pseudoequatorial position of the aldehyde group, respectively, and are used to designate half-chair conformers. trans and cis denote relative positions of the aldehyde to the ring oxygen. 
not clear from these PES with which the TS geometry is similar, i.e., boat or sofa, and whether boat/sofa like local minimum exists as an intermediate. Thus two half-chair geometries and boat/sofa forms were optimized by $a b$ initio DFT calculations, giving only two half-chair local minima and the boat transition state. For each geometry thus obtained, transition states for the aldehyde group rotation were located. The final results are shown in Figure 8. Selected geometric parameters for these geometries are given in Table II. In Figure 8 and Table II, abbreviations a' (pseudoaxial) and $\mathrm{e}^{\prime}$ (pseudoequatorial) are used to discriminate the two half-chair conformers. Also cis and trans positions of the aldehyde oxygen to the ring oxygen are denoted by $\mathrm{A}$ and $\mathrm{B}$, respectively, to designate these conformers.

The interconversion scheme in Figure 8 comprises 4 local minima, 4A, 4B, 5A, and 5B, and transition states connecting these structures. In $\mathrm{a}^{\prime}$ and $\mathrm{e}^{\prime}$ transformation, the boat structure is located as the transition state. In rotational transformations ( $4 \mathrm{~A}$ to $4 \mathrm{~B}$ and $5 \mathrm{~A}$ to $5 \mathrm{~B}$ ), we located two transition states for each.

trans $\mathrm{a}^{\prime}$ half-chair $(4 \mathrm{~A})$ is more stable than $\mathrm{e}^{\prime}$-form (5A) and cis a' half-chair (4B) by $1.2 \mathrm{kcal} \mathrm{mol}^{-1}$ and $2.4 \mathrm{kcal} \mathrm{mol}^{-1}$, respectively. cis $\mathrm{e}^{\prime}$ half-chair form $(5 \mathrm{~B})$ is rather unstable. Assuming Bolzman distribution, the ratios of these conformers are $4 \mathrm{~A} / 5 \mathrm{~A} / 4 \mathrm{~B}=1 / 0.14 / 0.019$ $\left(30^{\circ} \mathrm{C}\right)$ and $1 / 0.044 / 0.0021\left(-80^{\circ} \mathrm{C}\right)$.

Barrier height for the ring inversion from the most stable $4 \mathrm{~A}$ to $5 \mathrm{~A}$ and that for the aldehyde group rotation from $4 \mathrm{~A}$ to $4 \mathrm{~B}$ were calculated to be $5.8 \mathrm{kcal} \mathrm{mol}^{-1}$ and $4.2 \mathrm{kcal} \mathrm{mol}^{-1}$, respectively. Thus calculated ring inversion barrier height of MAD is comparable with or slightly higher than that of cyclohexene $\left(5.2 \mathrm{kcal} \mathrm{mol}^{-1}\right.$, section 3 ). Bushweller and O'Neil reported the interconversion free energy barrier for cyclohexene and 3,4-dihydropyran to be $5.2 \mathrm{kcal} \mathrm{mol}^{-1}\left(-165^{\circ} \mathrm{C}\right)$ and $6.6 \pm 0.3 \mathrm{kcal} \mathrm{mol}^{-1}$ $\left(-140^{\circ} \mathrm{C}\right)$, respectively. ${ }^{5}$

MAD in this paper is in good agreement with or slightly lower $\left(0.8 \mathrm{kcal} \mathrm{mol}^{-1}\right)$ than the barrier height for 3,4-dihydropyran. Both works agree that 3,4-dihydro- pyran ring has higher interconversion barrier than cyclohexene.

NMR measurement suggests that these conformers interchange rather freely at $30^{\circ} \mathrm{C}$. Although calculated PES shows that both ring puckering and aldehyde group rotation have interconversion barrier, NMR suggests that the ring motion becomes freezed by lowering the temperature. Above results show that at $-80^{\circ} \mathrm{C}$ the trans $\mathrm{a}^{\prime}$ half-chair form (4A) exists predominantly.

Acknowledgments. We are grateful to Professor Tokio Yamabe at Kyoto University for useful discussions. We thank Dr. Kazuhiro Suzuoki of Asahi Chemical Industry Co. for helpful advice.

\section{REFERENCES}

1. Y. Kitahama, H. Ohama, and H. Kobayashi, J. Polym. Sci., B, 5, 1019 (1967).

2. Y. Kitahama, J. Polym. Sci., A-1, 6, 2309 (1968).

3. J. Maslinska-Solich, A. Macionga, and R. Turczyn, Polish J. Appl. Chem., 39, 467 (1995).

4. J. Maslinska-Solich, A. Macionga, and R. Turczyn, Reactive \& Functional Polymers, 26, 35 (1995).

5. C. H. Bushweller and J. W. O'Neil, Tetrahedron Lett., 53, 4713 (1969).

6. E. L. Eliel, M. Manoharan, K. M. Pietrusiewicz, and K. D. Hargrave, Org. Magn. Reson., 21, 94(1983).

7. SpecInfo(R) 3.1.6.0, Chemical Concepts GmbH, 1996.

8. UniChem(R) chemistry codes, APG-5505 3.0, Cray Research, Inc., 1995.

9. (a) A. D. Becke, J. Chem. Phys., 84, 4524 (1986); (b) J. P. Perdew, Phys. Rev., 33, 8822 (1986).

10. F. A. I. Anet, in "The Comformational Analysis of Cyclohexenes, Cyclohexadienes, and Related Hydroaromatic Compounds," P. W. Rabideau, Ed., VCH Publishers, New York, N.Y., 1989, Chapter 1.

11. M. M. J. Tecklenburg and J. Laane, J. Am. Chem. Soc., 111, 6920 (1989).

12. F. A. L. Anet, D. I. Freedberg, J. W. Storer, and K. N. Houk, J. Am. Chem. Soc., 114, 10969 (1992).

13. C. W. Andrews, B. Fraser-Reid, and J. P. Bowen, J. Am. Chem. Soc., 113, 8293 (1991). 